\title{
Boosting bioethanol production from Eucalyptus wood by whey incorporation
}

\author{
Manuel Cunha ${ }^{1}$, Aloia Romaní ${ }^{1}$, Margarida Carvalho, Lucília Domingues* \\ CEB - Centre of Biological Engineering, University of Minho, Campus Gualtar, 4710-057 Braga, Portugal
}

\section{A R T I C L E I N F O}

\section{Keywords:}

Bioethanol

Cheese whey

Lignocellulose biomass

$\beta$-Galactosidase

High solid loadings

\begin{abstract}
A B S T R A C T
The mixture of Eucalyptus globulus wood (EGW) and cheese whey powder (CWP) was proposed for intensification of simultaneous saccharification and fermentation (SSF) at high temperature and solid loadings using the industrial Saccharomyces cerevisiae Ethanol Red ${ }^{\circledR}$ strain. High ethanol concentration $(93 \mathrm{~g} / \mathrm{L})$, corresponding to $94 \%$ ethanol yield, was obtained at $35^{\circ} \mathrm{C}$ from $37 \%$ of solid mixture using cellulase and $\beta$-galactosidase enzymes (24.2 FPU/g and 20.0 U/g, respectively). The use of CWP mixed with pretreated EGW increased the ethanol concentration in 1.5-fold, in comparison with SSF experiments without CWP for both Ethanol Red ${ }^{\circledR}$ and CEN.PK113-7D strains. Moreover, 1.4-fold higher ethanol concentration was obtained with Ethanol Red ${ }^{\circledR}$, in comparison with CEN.PK113-7D strain. Ethanol Red ${ }^{\circledR}$ strain was genetically engineered for $\beta$-galactosidase production in order to advance towards a fully integrated process. This work shows the feasibility of attaining high ethanol concentrations in second generation bioprocesses by a multi-waste valorization approach.
\end{abstract}

\section{Introduction}

Bioethanol is the most widely used biofuel worldwide, partially able to replace fossil fuels, reducing the environmental impact of greenhouse gas emissions (Balat, 2011). Currently, bioethanol is produced from sucrose and/or starch from raw materials such as sugarcane and maize (first generation biofuel) (Rodionova et al., 2017). Nevertheless, the use of these raw materials poses sustainability concerns being necessary the search of alternative renewable raw materials for biofuels production (Menon and Rao, 2012).

Lignocellulosic feedstock is considered an interesting alternative since it is available in amounts high enough to sustain large-scale production of second generation bioethanol (Cai et al., 2017). In comparison with starchy raw materials, lignocellulosic biomass shows a complex structure that hinders the polysaccharide fractionation. Pretreatment is mandatory to improve the accessibility of lignocellulosic sugars. Hydrothermal treatment (also known as autohydrolysis or liquid hot water) is an environmentally-friendly treatment that has been successfully used for the bioethanol production by simultaneous saccharification and fermentation (SSF) from lignocellulosic feedstocks (such as hardwoods and agro-industrial residues) (Romaní et al., 2012; Vargas et al., 2015; Dominguez et al., 2017). Hydrothermal treatment solubilizes hemicellulose fraction yielding a solid phase composed mainly of cellulose and lignin, which limits the final ethanol concentration. For instance, the highest ethanol production obtained from hydrothermally pretreated eucalyptus wood at high solid loading was $67 \mathrm{~g} / \mathrm{L}$ (Romaní et al., 2012). Thus, one of the limitations of lignocellulose-to-ethanol process is the difficulty of using high solid loading to attain elevated ethanol concentration (required to reduce distillation costs) (Kroppam et al., 2014). The production of ethanol by SSF instead of separate hydrolysis and fermentation (SHF) shows several benefits, such as the reduced investment costs and the reduction of end-product inhibition of enzymatic hydrolysis (Olofsson et al., 2008). Nevertheless, the fermentation temperature is another critical condition for productive simultaneous saccharification and fermentation processes as the optimal temperature for enzymatic hydrolysis is higher than the optimal for yeast fermentation. Hence, robust thermotolerant yeast are mandatory for working under the required intensified conditions (high temperature and solid loadings) (Kelbert et al., 2016).

Other raw materials have been used for ethanol production, such as whey residue obtained from the production of cheese and casein (Jin et al., 2016). Cheese whey can be processed by physical and thermal treatments to obtain whey powder, whey protein concentrate, whey protein isolate and whey permeate or by biotechnological processing to produce value-added compounds such as animal feed, bioprotein, single cell protein (SCP), probiotics, organic acids, biofuels, enzymes, carotenoids, biological gums, exopolysaccharides, and bioplastics (Yadav et al., 2015).

\footnotetext{
* Corresponding author.

E-mail address: luciliad@deb.uminho.pt (L. Domingues).

${ }^{1}$ Both authors contributed equally to this work.
} 
Whey demand is increasing for manufacturing of whey protein due to high functional and nutritional values with application in pharmaceutical and food industry. Separation of whey protein requires additional steps of ultrafiltration or diafiltration which generate high volumes of a lactose-rich stream (whey permeate). The fermentation of lactose in cheese whey or whey permeate into ethanol is an interesting valorization solution for the important environmental problem caused by this high organic matter stream (Guimarães et al., 2010). The use of cheese whey powder (CWP) or concentrated cheese whey permeate improves the economics of process since high ethanol concentration can be obtained reducing distillation costs (Kargi, and Ozmihc1, 2006). Besides, CWP has also been used as low-cost protein source to nutritionally supplement lignocellulosic to ethanol fermentations (TomásPejó et al., 2012; Kelbert et al., 2015).

Saccharomyces cerevisiae is the most widely used microorganism in industrial ethanol processes due to its remarkable fermentation capacity (Oliveira et al., 2011; Guimarães et al., 2010; Domingues et al., 2005). However, ethanol production from lactose by $S$. cerevisiae requires the addition of $\beta$-galactosidase enzyme, which catalyzes the hydrolysis of lactose into glucose and galactose, as wild-type $S$. cerevisiae strains are unable to consume lactose. One of the strategies to avoid the prior hydrolysis of lactose by commercial enzymes would be to develop a recombinant $S$. cerevisiae strain able to secrete $\beta$-galactosidase into the culture medium. This approach has already been reported using laboratory strains as host microorganisms (Domingues et al., 2002; Oliveira et al., 2007). Domingues et al. (2002) constructed a flocculent $S$. cerevisiae strain secreting an extracellular Aspergillus niger $\beta$-galactosidase, encoded by the lacA gene. For that, the auxotrophic strain NCYC869-A3 was transformed with the plasmid pVK1.1, harboring the lacA gene under the regulation of $S$. cerevisiae ADH1 promoter and terminator. On the other hand, Oliveira et al. (2007) integrated the lacA gene into the genome of NCYC869-wt strain, using the delta sequences from retrotransposon Ty1 as target sites for gene integration. A recombinant NCYC869 strain was obtained (NCYC869/ $\mathrm{p} \delta$ neo + lacA), harboring multi-copies of the $\beta$-galactosidase expression cassette which were stably maintained after 8 sequential batch experiments. Both strains were able to secrete $\beta$-galactosidase at interesting titers. However, in biorefineries yeast cells must perform under harsh conditions, including the presence of inhibitors resulting from biomass hydrolysis. In this context, robust industrial yeast strains are preferred over laboratory strains due to their superior tolerance to these compounds (Pereira et al., 2014; Cunha et al., 2015; Romaní et al., 2015; Costa et al., 2017).

Integration of cheese whey into lignocellulose-to-ethanol processes in a multi-wastes valorization approach could allow the improvement and intensification of fermentation conditions to attain high ethanol concentrations by increasing the carbon source content in the substrate. Recently, this strategy of whey incorporation has been proposed for raw materials from first generation bioethanol such as: wheat flour (Jin et al., 2016), potato tubers and starch (Nakamura et al., 2012). Research works using this approach with lignocellulosic raw materials as substrate are still limited (Oke et al., 2016) and reported final ethanol concentration below 50 g/L (Fischer et al., 2013; Coman et al., 2015; Ferreira et al., 2015). Moreover, integrated bioprocessing, which combines enzyme production, hydrolysis and fermentation in a single process, is recognized as having potential to reduce capital cost involved in lignocellulose-to-ethanol processes (Hasunuma and Kondo, 2012).

In this work, hydrothermally pretreated Eucalyptus globulus wood (EGW) was mixed with cheese whey powder (CWP) to produce bioethanol by simultaneous saccharification and fermentation under intensified conditions (high temperature and solid loadings). Operational conditions (cellulase, $\beta$-galactosidase and CWP loadings) were optimized for ethanol production using $S$. cerevisiae Ethanol $\operatorname{Red}^{\circledR}$ strain and compared with ethanol performance obtained with a laboratory yeast strain (CEN.PK113-7D). In addition, Ethanol Red ${ }^{\circledast}$ strain was
Table 1

Chemical composition of Eucalyptus globulus wood (EGW), autohydrolyzed EGW and cheese whey powder (CWP).

a) Chemical composition of EGW and autohydrolyzed EGW, oven-dry basis

\begin{tabular}{lll}
\hline & $\mathrm{g} / 100 \mathrm{~g}$ of EGW & $\mathrm{g} / 100 \mathrm{~g}$ of autohydrolyzed EGW \\
\hline Glucan & $44.7 \pm 0.81$ & $63.4 \pm 1.49$ \\
Xylan & $16.0 \pm 0.35$ & $0.95 \pm 0.25$ \\
Arabinan & $1.1 \pm 0.05$ & - \\
Acetyl groups & $3.0 \pm 0.28$ & - \\
Klason Lignin & $27.7 \pm 0.6$ & $36.0 \pm 1.3$ \\
Extractives & $2.0 \pm 0.6$ & - \\
\hline
\end{tabular}

b) Chemical composition of cheese whey powder (CWP), ( $\mathrm{g} / 100 \mathrm{~g}$ oven-dry basis)

\begin{tabular}{lc}
\hline Lactose & $60 \pm 0.58$ \\
Protein & $12 \pm 0.95$ \\
Ashes & $<1$ \\
\hline
\end{tabular}

genetically engineered for the production of an extracellular $\beta$-galactosidase in order to advance towards the development of an integrated and intensified process.

\section{Material and methods}

\subsection{Raw materials and analysis of the raw materials}

Eucalyptus globulus wood (EGW) was obtained from pulp and paper factory (ENCE, NW Spain), milled to pass an $8 \mathrm{~mm}$ screen, air-dried, homogenized and stored in a single lot and dry place until its use. EGW were analyzed for chemical composition (Table 1) following the procedure described by NREL standards (Quantitative acid hydrolysis, NREL-TP-510-42618). Cheese whey powder (CWP) was kindly provided by Lactogal company (Porto, Portugal). Lactose content in CWP was directly analyzed by HPLC with a Aminex HPX-87H column, eluent $\mathrm{H}_{2} \mathrm{SO}_{4} 0.005 \mathrm{M}$ at $60{ }^{\circ} \mathrm{C}$ and a flow rate of $0.6 \mathrm{~mL} / \mathrm{min}$. The crude protein content of CWP was calculated in basis of $\mathrm{N}$ determined by Kjeldahl method with appropriated factor 6.25 (Jones, 1941). Ashes was determined by NREL-TP-510-42622 procedure. Chemical composition of CWP was also shown in Table 1.

\subsection{Autohydrolysis pretreatment of Eucalyptus globulus wood}

EGW was submitted to autohydrolysis treatment. EGW was mixed with water at liquid-to-solid ratio (LSR) of $8 \mathrm{~kg}$ water per $\mathrm{kg}$ of oven-dry EGW in a pressurized reactor (Parr Instruments Company, Moline, IL). The autohydrolysis treatment was carried out at $150 \mathrm{rpm}$ and heated, following the heating profile (Romaní et al., 2010) up to the desired temperature $\left(\mathrm{T}_{\mathrm{MAX}}=230^{\circ} \mathrm{C}\right)$. The operational conditions were chosen on the basis of reported data (Romaní et al., 2012). Once the intended temperature was reached, the experiment was cooled and the liquid and solid phase (autohydrolyzed EGW) were separated by filtration for analysis of chemical composition as described below.

\subsection{Strains and cultivation conditions for genetic constructions}

Escherichia coli strain NZY5a (Nzytech) used for plasmid construction was grown at $37^{\circ} \mathrm{C}$ in Luria-Bertani (LB) medium containing $100 \mathrm{mg} / \mathrm{L}$ ampicillin. Saccharomyces cerevisiae Ethanol Red ${ }^{\circledR}$ cells were transformed by LiAC/SS carrier DNA/PEG method (Gietz and Schiestl, 2007). After transformation, cells were plated on standard yeast peptone dextrose (YPD) agar plates peptone $2 \%(\mathrm{w} / \mathrm{v})$, glucose $2 \%(\mathrm{w} / \mathrm{v})$, yeast extract $1 \%(\mathrm{w} / \mathrm{v})$ and agar $2 \%(\mathrm{w} / \mathrm{v})$ supplemented with $200 \mathrm{mg} /$ L geneticin (G418) and X-gal $(40 \mu \mathrm{g} / \mathrm{mL})$ and allowed to grow until colonies appeared. Cells expressing $\beta$-galactosidase, i.e., those carrying the plasmid, form blue colonies in X-gal plates. 


\subsection{Plasmid construction}

The pMC1 plasmid was modified from the pVK1.1 plasmid described by Kumar et al. (1992) by inserting a dominant selection marker, the GEN3 module, allowing the plasmid to be used in prototrophic strains. The GEN3 module consists of the kanamycin-resistance gene under the control of the $S$. cerevisiae TEF2 promoter and terminator sequences and confers resistance to G418/geneticin. For this, pVK1.1 was digested with SphI, removing the lacA expression cassette containing the Aspergillus niger lacA gene (coding for an extracellular $\beta$ galactosidase) flanked by the $S$. cerevisiae ADH1 promoter and terminator. The obtained backbone, YEp24, was then digested with SalI. The GEN3 module was removed from pAGT351 plasmid with SalI, digested with SphI and ligated to the YEp24 backbone. The A. niger lacA cassette was then inserted back into the SphI site in YEp24_GEN3. The resulting plasmid was named pMC1 and verified by restriction digestion.

\subsection{Strains and cultivation conditions for SSF experiments}

The yeast strains used in this work were Saccharomyces cerevisiae Ethanol Red ${ }^{\circledR}$, CEN.PK 113-7D and recombinant Ethanol Red ${ }^{\circledR}$-pMC1. Wild-type stock cultures were maintained on standard YPD-agar plates at $4{ }^{\circ} \mathrm{C}$ and for recombinant Ethanol Red $^{\circledR}$-pMC1, YPD-agar plates were supplemented with $200 \mathrm{mg} / \mathrm{L}$ geneticin (G418). Cells were inoculated in 250 Erlenmeyer flasks with $100 \mathrm{~mL}$ of YPD medium at $30^{\circ} \mathrm{C}$ and $200 \mathrm{rpm}$ for $15 \mathrm{~h}$. For recombinant Ethanol Red ${ }^{\circledR}$-pMC1 cells, YPD was supplement with $200 \mathrm{mg} / \mathrm{L}$ geneticin (G418). The cell suspension was aseptically collected by centrifugation for $15 \mathrm{~min}$ at $8500 \mathrm{~g}, 4^{\circ} \mathrm{C}$ and resuspended in $0.9 \% \mathrm{NaCl}$ to a concentration of $200 \mathrm{mg}$ fresh yeast $/ \mathrm{mL}$. The fermentation experiments were inoculated with approximately $7.5 \mathrm{mg}$ fresh yeast/ $\mathrm{mL}$.

\subsection{Simultaneous saccharification and fermentation: experimental plan and statistical analysis}

Simultaneous saccharification and fermentation (SSF) assays of mixture of EGW and CWP were carried out following a Box-Behnken, second-order design based on the three-level incomplete factorial design (3 factors with three replicates of the central point, 15 total experiments). The enzymes used in this work, cellulase (Cellic CTec2) and $\beta$-galactosidase (Saphera 2600L), were kindly supplied by Novozymes (Bagsvaerd, Denmark). The Cellic CTec2 was used for saccharification of cellulose (present in pretreated EGW) and Saphera was used for hydrolysis of lactose (present in CWP). The matrix of experimental plan was shown in Table 2 . The independent variables studied were: $\%$ of cheese whey or $x_{1}, \beta$-galactosidase loading ( $\mathrm{U} / g$ of lactose in cheese whey) or $x_{2}$ and cellulase loading (FPU/g of autohydrolyzed EGW) or $x_{3}$. The amount of lignocellulosic substrate (pretreated EGW) was fixed in $25 \%$. The independent variables can be correlated with dependent variables by a second-polynomial equation following the expression:

$$
\begin{aligned}
y_{i}= & \beta_{0 i}+\beta_{1 i} x_{1}+\beta_{2 i} x_{2}+\beta_{3 i} x_{3}+\beta_{11 i} x_{1}^{2}+\beta_{22 i} x_{2}^{2}+\beta_{33 i} x_{3}^{2}+\beta_{12 i} x_{1} x_{2} \\
& +\beta_{13 i} x_{1} x_{3}+\beta_{23 i} x_{2} x_{3}
\end{aligned}
$$

where, $y i(i=1-2)$ are the dependent variables (corresponding to Ethanol concentration or Ethanol yield); $x_{1}, x_{2}$ and $x_{3}$ value of independent variables; $\beta_{0 i}, \beta_{1 i}, \beta_{2 i}, \beta_{3 i}$ are regression coefficients calculated from experimental data by multiple regression using the leastsquares method. The experimental data were fitted to the proposed model using commercial software (Statgraphics). The goodness of model fitting was evaluated by the coefficient determination $\mathrm{R}^{2}$ and the statistical significance by the Fisher's F-test for analysis of variable with a $95 \%$ confidence level.

The SSF assays were carried out in a $100 \mathrm{~mL}$ Erlenmeyer flask at $35^{\circ} \mathrm{C}$ and $\mathrm{pH}=5$ in an orbital shaker $(140 \mathrm{rpm})$. Pretreated EGW $(25 \%$ of insoluble solids) and CWP (at soluble solid loading in the range
Table 2

Operational conditions (dimensional and dimensionless independent variables): run 1-15 experiments of experimental Box-Behnken design, run 16 and 17 (optimized condition, with and without cheese whey powder) using Ethanol Red $^{\oplus}$ strain and run 18 and 19 (optimized condition, with and without cheese whey powder using CEN.PK113-7D

\begin{tabular}{|c|c|c|c|c|c|c|}
\hline \multirow[t]{2}{*}{ Run } & \multicolumn{3}{|c|}{ Dimensional independent variables } & \multicolumn{3}{|c|}{$\begin{array}{l}\text { Normalized and independent } \\
\text { dimensionless variables }\end{array}$} \\
\hline & $\begin{array}{l}\text { Cheese } \\
\text { whey (\%) }\end{array}$ & $\begin{array}{l}\beta \text {-Galactosidase } \\
(\mathrm{U} / \mathrm{g})\end{array}$ & $\begin{array}{l}\text { Cellulase } \\
\text { (FPU/g) }\end{array}$ & $x_{1}$ & $x_{2}$ & $x_{3}$ \\
\hline 1 & 8.5 & 5 & 18.5 & -1 & -1 & 0 \\
\hline 2 & 25.5 & 5 & 18.5 & 1 & -1 & 0 \\
\hline 3 & 8.5 & 20 & 18.5 & -1 & 1 & 0 \\
\hline 4 & 25.5 & 20 & 18.5 & 1 & 1 & 0 \\
\hline 5 & 8.5 & 12.5 & 12 & -1 & 0 & -1 \\
\hline 6 & 25.5 & 12.5 & 12 & 1 & 0 & -1 \\
\hline 7 & 8.5 & 12.5 & 25 & -1 & 0 & 1 \\
\hline 8 & 25.5 & 12.5 & 25 & 1 & 0 & 1 \\
\hline 9 & 17.0 & 5 & 12 & 0 & -1 & -1 \\
\hline 10 & 17.0 & 20 & 12 & 0 & 1 & -1 \\
\hline 11 & 17.0 & 5 & 25 & 0 & -1 & 1 \\
\hline 12 & 17.0 & 20 & 25 & 0 & 1 & 1 \\
\hline 13 & 17.0 & 12.5 & 18.5 & 0 & 0 & 0 \\
\hline 14 & 17.0 & 12.5 & 18.5 & 0 & 0 & 0 \\
\hline 15 & 17.0 & 12.5 & 18.5 & 0 & 0 & 0 \\
\hline 16 & 10.6 & 20 & 24.23 & -0.749 & 1 & 0.881 \\
\hline 17 & 0 & 20 & 24.23 & - & 1 & 0.881 \\
\hline 18 & 10.6 & 20 & 24.23 & -0.749 & 1 & 0.881 \\
\hline 19 & 0 & 20 & 24.23 & - & 1 & 0.881 \\
\hline
\end{tabular}
strain).

8.5-25.5\%, Table 2) were used as substrates in SSF assays. Autohydrolyzed EGW and water were sterilized at $121^{\circ} \mathrm{C}$ for $20 \mathrm{~min}$. CWP was pasteurized at $60{ }^{\circ} \mathrm{C}$ for $60 \mathrm{~min}$ and added aseptically to autohydrolyzed EGW. Enzymes were added to SSF experiments at loadings shown in Table 2. Samples were withdrawn from experiments at desired times, centrifuged ( $6000 \mathrm{rpm}$ for $10 \mathrm{~min}$ ) and analyzed by HPLC for lactose, glucose, galactose and ethanol concentration. Ethanol yield was calculated as follows:

EtOH yield $(\%)=\frac{[E t O H]_{\max }}{[L] \cdot 0.53+[f B 1.11] 0.51} \cdot 100$

where, $[\mathrm{EtOH}]_{\max }$ is the maximal concentration obtained in SSF experiments $(\mathrm{g} / \mathrm{L}),[\mathrm{L}]$ is the concentration of lactose in SSF experiments considering the CWP percentage, 0.53 and 0.51 are conversion factors for lactose and glucose to ethanol based on stoichiometric biochemistry of yeast, respectively. [B] is dry pretreated EGW concentration at the end of SSF assays, $f$ is glucan fraction in pretreated EGW $(\mathrm{g} / \mathrm{g}), 1.111$ is the stoichiometric factor that converts glucan to equivalent glucose. Final volume at the end of the SSF experiments was corrected taking into account the solubilized fraction of EGW and CWP during the enzymatic hydrolysis. Considering this, the potential fermentable sugars of SSF assays was in the range of $166-275.5 \mathrm{~g} / \mathrm{L}$.

\subsection{Enzymatic activities}

The activity of Cellic CTec2 was measured by Filter Paper assay following the procedure described in Ghose (1987), corresponding to $123 \mathrm{FPU} / \mathrm{mL}$. The activity of Saphera was measured as the release of $p$ nitrophenol from $p$-nitrophenyl- $\beta$-D-galactopyranoside ( $p N P G)$, as previously described in Domingues et al. (2004). Samples were incubated with $1.7 \mathrm{mmol} / \mathrm{dm}^{3}$ substrate in $0.075 \mathrm{~mol} / \mathrm{dm}^{3} \mathrm{Na}$ acetate buffer, $\mathrm{pH}$ 4.5 , for $10 \mathrm{~min}$ at $65^{\circ} \mathrm{C}$. The $\mathrm{pH}$ was raised to 10 with $1 \mathrm{~mol} / \mathrm{dm}^{3}$ $\mathrm{Na}_{2} \mathrm{CO}_{3}$ and the activity was measured spectrophotometrically at $405 \mathrm{~nm}$ on Synergy HT Multi-Mode Microplate Reader (BioTek). The activity of Saphera was $1471.7 \mathrm{U} / \mathrm{mL}$. One unit of activity was defined as the amount of enzyme that hydrolyzed $1 \mu \mathrm{mol} p \mathrm{NPG} / \mathrm{min}$ at $65^{\circ} \mathrm{C}$. Moreover, activity of $\beta$-galactosidase secreted by recombinant Ethanol $\operatorname{Red}^{\circledast}$ strain was also measured following the same procedure. 
a)

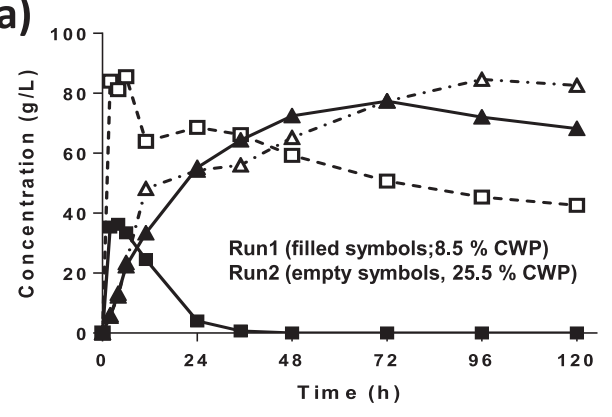

c)

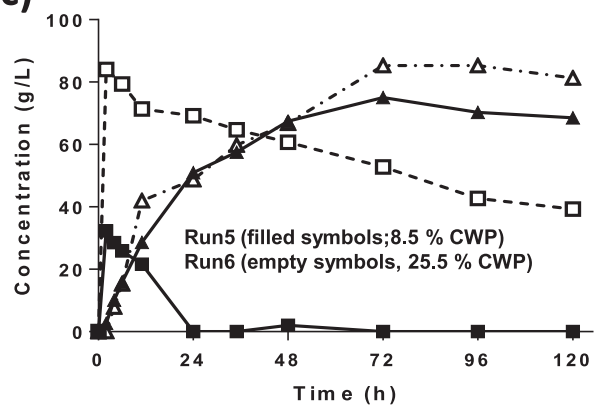

e)
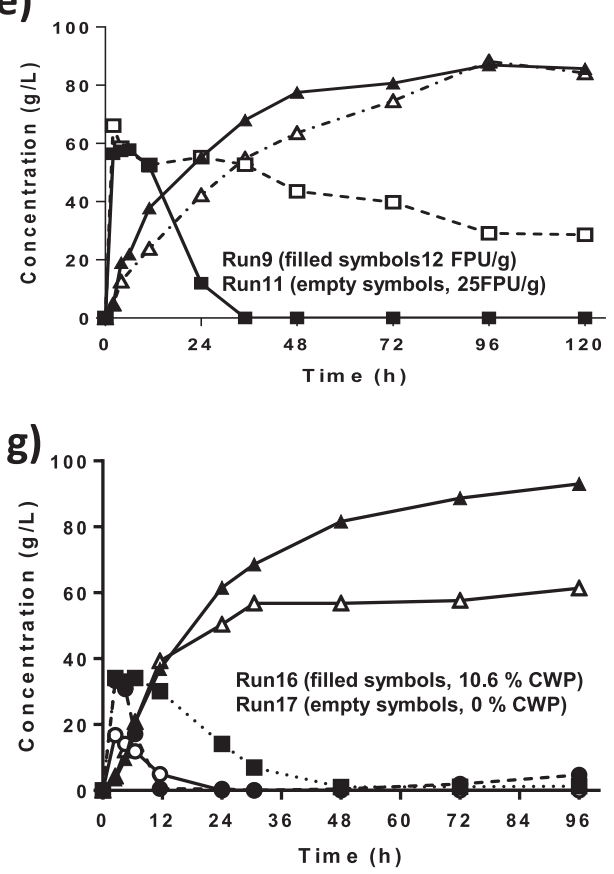

b)

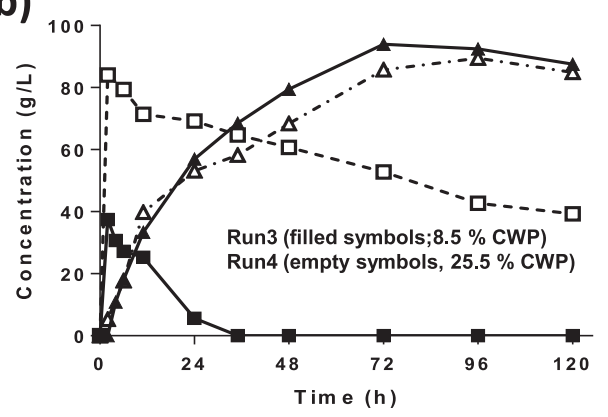

d)

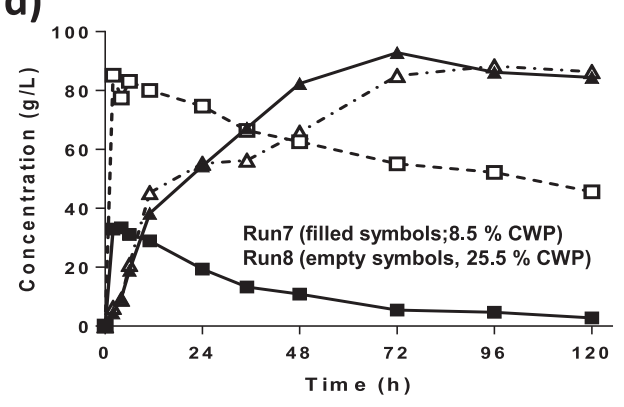

f)

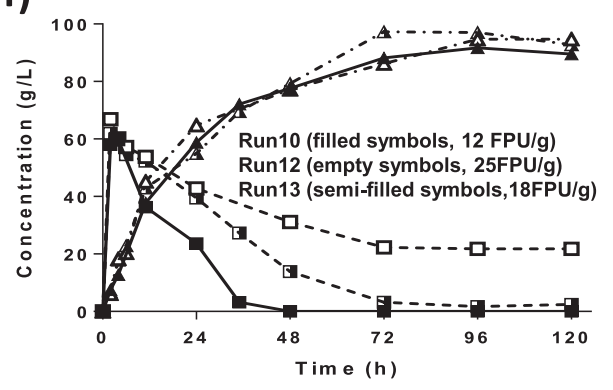

h)

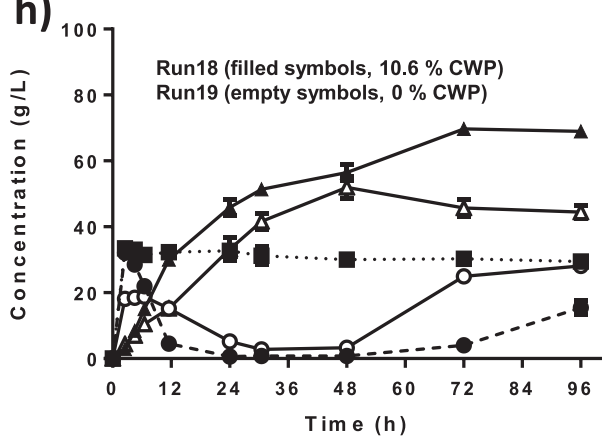

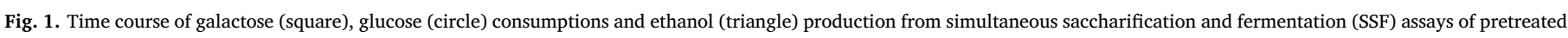

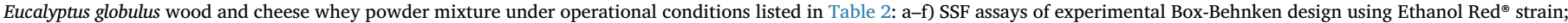

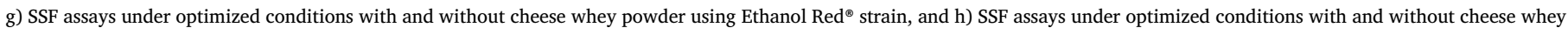
powder using CEN.PK113-7D strain.

\section{Results and discussion}

3.1. Hydrothermally pretreated Eucalyptus globulus and selection of operational conditions for simultaneous saccharification and fermentation

EGW was subjected to hydrothermal treatment (or autohydrolysis) at $230^{\circ} \mathrm{C}$ (conditions optimized by Romaní et al., 2012). Autohydrolysis treatment solubilizes the hemicellulose fraction and alters the recalcitrant structure of EGW, improving the enzymatic saccharification of cellulose (Romaní et al., 2010). The chemical composition of pretreated EGW was shown in Table 1. The autohydrolysis treatment allowed the glucan enriched of EGW from 44.7 to $63.4 \%$. After treatment, $69.9 \mathrm{~g}$ of hydrothermally pretreated EGW per $100 \mathrm{~g}$ of raw material were recovered. The glucan recovery was $99.2 \%$ considering the glucan present in the raw material. Pretreated EGW was previously used as substrate in SSF optimization at high solid loadings for ethanol production in which $67.4 \mathrm{~g} / \mathrm{L}$ of ethanol was achieved at liquid to solid ratio of $4 \mathrm{~g}$ of liquid per $\mathrm{g}$ of pretreated EGW (corresponding to $25 \%$ of solids) and Celluclast $1.5 \mathrm{~L}$ loading of 16 FPU per $\mathrm{g}$ of substrate (Romaní et al., 2012). 
Table 3

Sugars (lactose, glucose and galactose) concentration and dependent variables (ethanol concentration and ethanol yield) obtained from simultaneous saccharification and fermentation assays of Eucalyptus wood and cheese whey mixture using Ethanol Red ${ }^{\circledR}$ strain (run 1-17) and CEN.PK113-7D strain (run 18 and 19).

\begin{tabular}{llllll}
\hline Run & $\begin{array}{l}\text { Lactose } 0 \mathrm{~h} \\
(\mathrm{~g} / \mathrm{L})\end{array}$ & $\begin{array}{l}\text { Glucose } 11 \mathrm{~h} \\
(\mathrm{~g} / \mathrm{L})\end{array}$ & $\begin{array}{l}\text { Galactose } \\
120 \mathrm{~h} \\
(\mathrm{~g} / \mathrm{L})\end{array}$ & $\begin{array}{l}\text { Ethanol } \\
\text { concentration }(\mathrm{g} / \\
\mathrm{L}) \\
\text { or } y 1\end{array}$ & $\begin{array}{l}\text { Ethanol } \\
\text { yield } \\
(\%) \text { or } y 2\end{array}$ \\
& & & & 77.36 & 82.75 \\
\hline 1 & 51.08 & 0.00 & 0.00 & 82.59 & 60.96 \\
2 & 154.08 & 0.00 & 42.63 & 93.98 & 100.53 \\
3 & 53.66 & 0.00 & 0.00 & 89.46 & 66.03 \\
4 & 152.74 & 0.00 & 0.00 & 75.02 & 80.24 \\
5 & 51.97 & 0.24 & 0.00 & 85.32 & 62.98 \\
6 & 152.07 & 1.32 & 12.81 & 92.91 & 99.38 \\
7 & 52.02 & 0.00 & 2.79 & 88.33 & 76.10 \\
8 & 151.23 & 1.91 & 45.64 & 86.95 & 80.30 \\
9 & 107.24 & 1.03 & 0.00 & 91.74 & 77.17 \\
10 & 101.05 & 0.00 & 0.00 & 88.17 & 82.88 \\
11 & 102.08 & 1.30 & 0.00 & 94.69 & 87.51 \\
12 & 0.00 & 2.53 & 21.76 & 99.98 & 85.17 \\
13 & 100.97 & 0.00 & 3.00 & 97.31 & 83.46 \\
14 & 101.84 & 0.00 & 2.47 & 95.35 & 83.30 \\
15 & 101.23 & 0.00 & 1.87 & 93.03 & 70.10 \\
16 & 62.30 & 0.51 & 1.29 & 61.38 & 62.68 \\
17 & 0 & 0.00 & - & 45.95 & \\
18 & 61.86 & 4.20 & 29.17 & & \\
19 & 0 & 15.55 & - & & \\
\hline
\end{tabular}

* Galactose concentration (g/L) at $96 \mathrm{~h}$.

In this work, cheese whey powder was mixed with hydrothermally pretreated EGW to provide an additional source of carbon (lactose) and protein in order to intensify the lignocellulose-to-ethanol process. Therefore, the percentage of hydrothermally pretreated EGW was fixed based on the above described work (Romaní et al., 2012). The percentage of CWP and the enzymes loadings (cellulase and $\beta$-galactosidase) were evaluated and optimized using an experimental BoxBehnken design. Levels of independent variables evaluated (CWP, cellulase and $\beta$-galactosidase) were listed in Table 2 . The percentage of CWP varied in the range of $8.5-25.5 \%$ corresponding to $5-15 \%$ of lactose, these concentrations were chosen based on literature (Guimarães et al., 2008). The range of $\beta$-galactosidase (5-20 U/g lactose) and cellulase (12-25 FPU/g of pretreated EGW) loadings were also selected based on published works (Romaní et al., 2014; Jin et al., 2016).

\subsection{Co-fermentation of substrates for ethanol production by simultaneous} saccharification and fermentation

SSF assays were carried out under conditions listed in Table 2. Time course of galactose consumption and ethanol production are displayed in Fig. 1. The operational conditions evaluated have a clear effect on sugars consumption and ethanol production using the mixture of substrates (EGW and CWP). In all of the evaluated conditions, lactose was hydrolyzed into glucose and galactose within $3 \mathrm{~h}$ of SSF process (data not shown). Glucose from lactose hydrolysis was preferably fermented within $11 \mathrm{~h}$ of fermentation in all assays (Table 3). This fact is probably due to the catabolite repression phenomenon (Belinchón and Gancedo, 2003; Trigueros et al., 2016). Similar behavior was observed in the cofermentation of $25 \%$ of wheat and $16.7 \%$ of cheese permeate in which glucose was totally consumed and galactose uptake was lower (Jin et al., 2016).

In fact, SSF profiles showed clear differences in the galactose consumption depending on lactose concentration. Galactose was fermented by $S$. cerevisiae Ethanol Red $^{\circledR}$ within $24 \mathrm{~h}$ of fermentation at the lowest amount of CWP (8.5\%) evaluated (Fig. 1a-c, filled symbols). In these SSF assays, co-fermentation of glucose and galactose was clearly observed, being the glucose consumption rate higher than galactose a)

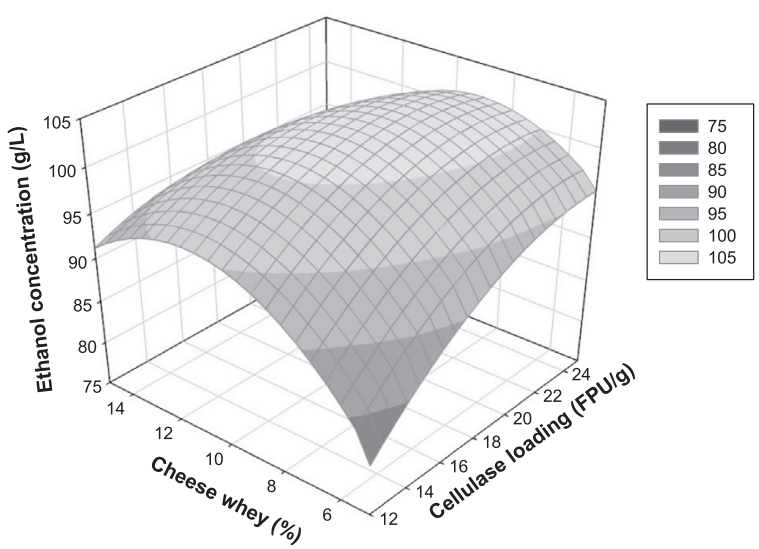

b)

$\beta$-galactosidase loading $=20 \mathrm{U} / \mathrm{g}$

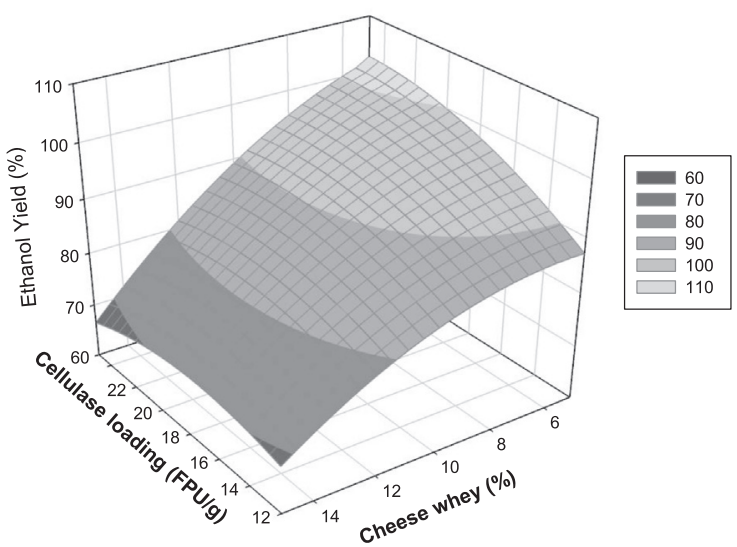

Fig. 2. Response surface as function of cellulase loading and cheese whey percentage (fixed $\beta$-galactosidase at $20 \mathrm{U} / \mathrm{g}$ of: a) ethanol production in $\mathrm{g} / \mathrm{L}$ ) and $\mathrm{b}$ ) ethanol yield in $\%$.

uptake rate (Table 3 and Fig. 1). On the other hand, the galactose consumption was lower than $30 \mathrm{~g} / \mathrm{L}$ when the percentage of CWP was the highest (25.5\%, see Fig. 1a-c, empty symbols). For SSF experiments with intermediate CWP percentage (17.0\%), galactose was consumed within $120 \mathrm{~h}$ of fermentation showing differences depending on the quantity of added cellulase enzyme (12-25 FPU/g). Galactose was totally consumed within $35 \mathrm{~h}$ of fermentation in runs 9 and 10 in which the cellulase loading was the lowest (12 FPU/g). In SSF assays (Fig. 1d, runs 11 and 12) where the cellulase loading was the highest (25 FPU/ $\mathrm{g}$ ), galactose was consumed more slowly in comparison with runs 9 and 10 (Fig. 1c). This fact is probably related to a lower saccharification of cellulose when using $12 \mathrm{FPU} / \mathrm{g}$ (Romaní et al., 2010), which reduces the glucose concentration in the medium and could improve the galactose consumption by alleviating catabolite repression.

Differences in the galactose consumption were directly related with ethanol production (Fig. 1 and Table 3). The highest ethanol production ( $99.98 \mathrm{~g} / \mathrm{L}$, corresponding to $87.51 \%$ of ethanol yield) was achieved at intermediate conditions (run 13 in Table 3). Ethanol concentration higher than $85 \mathrm{~g} / \mathrm{L}$ was obtained with $17 \%$ of CWP, independent of enzyme loadings used. Interestingly, high ethanol concentration ( $>90 \mathrm{~g} / \mathrm{L}$ ) was produced with the lowest CWP percentage (8.5\%) using cellulase loading of $25 \mathrm{FPU} / \mathrm{g}$ (run 3 and 7). Recent studies have shown the importance of the utilization of low cost materials as co-substrate for bioethanol production (Jin et al., 2016; Oke et al., 2016; Parashar 
a)

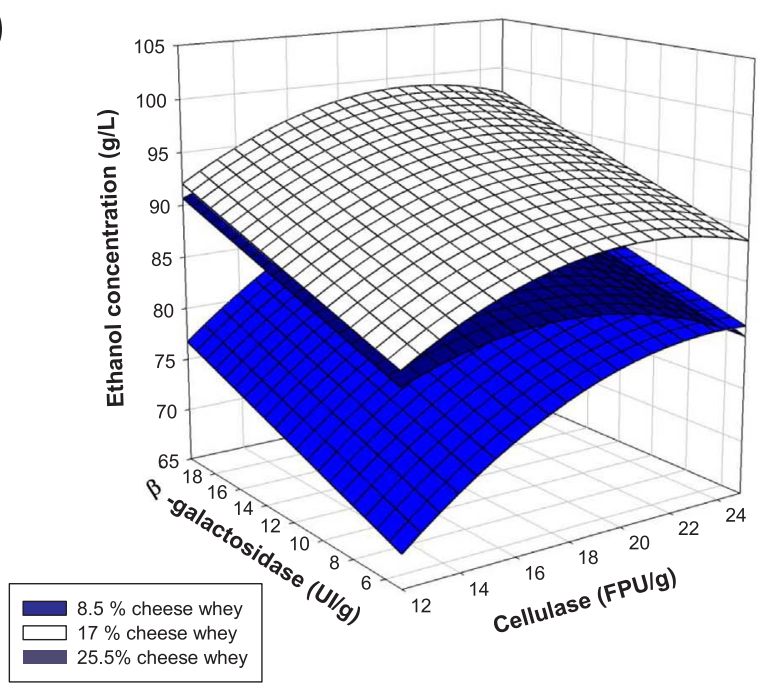

b)

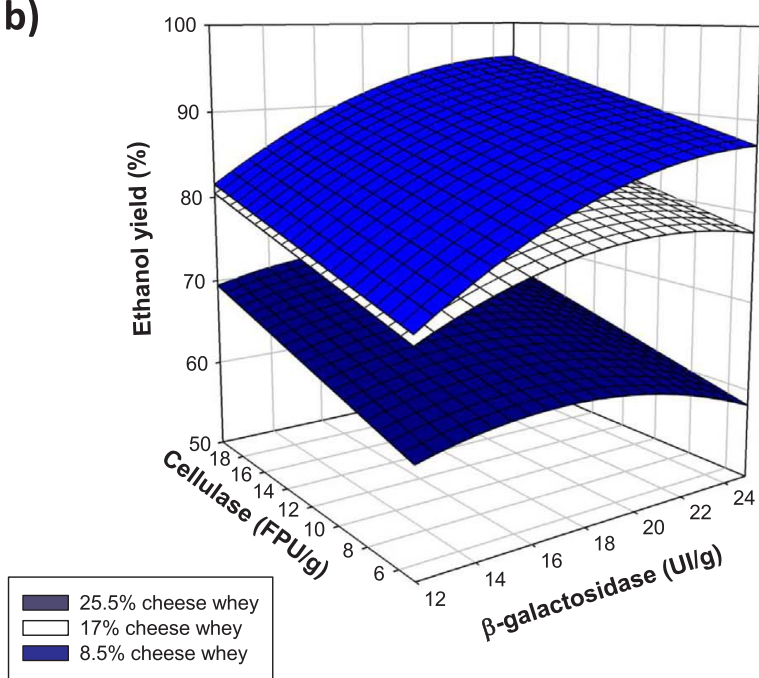

Fig. 3. Response surface as function of cellulase and $\beta$-galactosidase loadings (fixed cheese whey powder at $25.5,17$ and $8.5 \%$ ) of: a) ethanol production in $\mathrm{g} / \mathrm{L}$ and $\mathrm{b}$ ) ethanol yield in \%.

et al., 2016). However, just a few studies referred this approach in fermentations using lignocellulosic materials (Fischer et al., 2013, Coman et al., 2015; Ferreira et al., 2015). High ethanol concentration ( $>90 \mathrm{~g} / \mathrm{L}$ ) obtained in this work can be positively compared with literature using pretreated lignocellulosic biomass mixed with cheese whey. Ferreira et al. (2015) reported a maximal ethanol production of $49.65 \mathrm{~g} / \mathrm{L}$, obtained using $80 \mathrm{~g} / \mathrm{L}$ of pretreated sugarcane bagasse by sequential stages of sulfuric acid and $\mathrm{NaOH}$ pretreatments mixed with ricotta whey using Kluyveromyces marxianus CCT 7735 . In another study, steam exploded sugarcane bagasse $(30 \mathrm{~g} / \mathrm{L})$ was mixed with milk whey to produce $17.9 \mathrm{~g} / \mathrm{L}$ of ethanol (Fischer et al., 2013).

\subsection{Generalization of models and response surface methodology assessment}

Table 3 collected the studied dependent variables in this work (maximal ethanol concentration in $\mathrm{g} / \mathrm{L}$ (or $y_{1}$ ) and ethanol yield in $\%$ (or $y_{2}$ )), obtained from SSF assays. Experimental variables were correlated following the second-order polynomial Eq. (1) (shown in Section
2.6). The proposed mathematical models describing the CWP percentage $\left(x_{1}\right)$, beta-galactosidase $\left(x_{2}\right)$ and cellulase loadings $\left(x_{3}\right)$ as function and using normalized values are described by Eqs (3) and (4) for ethanol concentration $\left(y_{1}\right)$ and ethanol yield $\left(y_{2}\right)$, respectively.

$y_{1}=97.548+4.351 x_{2}+3.133 x_{3}-3.723 x_{1} x_{3} \quad\left(\mathrm{R}^{2}=0.904 ; \mathrm{F}=5.211\right)$

$$
\begin{aligned}
y_{2} & =85.354-13.465 x_{1}+4.094 x_{2}+3.126 x_{3}-4.991 x_{1}^{2}-4.231 x_{1} x_{3} \quad\left(\mathrm{R}^{2}\right. \\
& =0.964 ; \mathrm{F}=14.959)
\end{aligned}
$$

The statistical significance of the model (based on Fischer's $F$ parameter) showed the good fitting of evaluated variables $\left(R^{2}>0.9\right)$.

The effect of these independent variables (CWP percentage, cellulase and $\beta$-galactosidase loadings) were evaluated by response surface methodology assessment (RSM). RSM is a useful tool for the easy interpretation of independent variables effect on dependent variables (Kelbert et al., 2016). Fig. 2a and b show the effect of cheese whey powder percentage and cellulase enzyme loading on ethanol concentration and yield, with a fixed loading of $\beta$-galactosidase at $20 \mathrm{U} / \mathrm{g}$. As seen in Fig. 2a, ethanol concentration higher than $90 \mathrm{~g} / \mathrm{L}$ was obtained when CWP was $>12.75 \%$, independent of cellulase loading. CWP had a remarkable positive effect on ethanol concentration, while cellulase loading effect was lower. On the other hand, a cellulase loading $>17.9 \mathrm{FPU} / \mathrm{g}$ and $\mathrm{CWP}<16.2 \%$ was necessary to obtain ethanol yields higher than $90 \%$. The increase of cheese whey concentration influenced positively on ethanol concentration (with concentration higher than $100 \mathrm{~g} / \mathrm{L}$ of ethanol in the range of $12.75-21.25 \%$ of cheese whey or $7.5-12.5 \%$ of lactose) and negatively on ethanol yield (Table 3). Negative effect of lactose on ethanol yield was also observed by Sansonetti et al. (2010), who optimized the operational conditions of ricotta cheese whey fermentation for ethanol production by $K$. marxianus CBS 397.

Fig. 3 shows the effect of $\beta$-galactosidase and cellulase at different cheese whey percentages (25.5, 17 and $8.5 \%$ ) on ethanol concentration and ethanol yield. Interestingly, lower concentrations of ethanol were achieved operating at $25.5 \%$ of cheese whey in comparison with $17 \%$ of cheese whey (Fig. 3a). The inhibitory effect of concentrated whey media (lactose concentration in the range of $100-150 \mathrm{~g} / \mathrm{L}$ ) has been reported by several authors (Guimarães et al., 2010). The $\beta$-galactosidase and cellulase showed higher effect on ethanol production operating at low CWP (8.5\%). This fact might suggest an enzyme inhibition effect due to the high substrate loading (33.3-50.0\%) employed in this work. Fig. 3b shows similar ethanol yields (in the range of 70-80\%) obtained with 8.5 and $17 \%$ of cheese whey with low $\beta$-galactosidase loading $(12 \mathrm{U} / \mathrm{g})$, independently of cellulase loading.

\subsection{Optimization and model validation}

In order to optimize the SSF process of EGW and CWP mixture, an optimal condition was calculated to obtain the highest ethanol yield and final titer. For that, dependent variables $\left(y_{1}\right.$ and $\left.y_{2}\right)$ were used as response variable for the multiple response optimization of model. The model predicted a maximum ethanol concentration and ethanol yield using the following conditions of operation: $10.6 \%$ of cheese whey, $20.0 \mathrm{U}$ of $\beta$-galactosidase/g and 24.23 FPU of cellulase/g. The predicted ethanol concentration and ethanol yield were $99.96 \mathrm{~g} / \mathrm{L}$ and $100 \%$, respectively. To validate these results, additional SSF assay was carried out (Fig. 1g, run 16). Experimental data obtained from validation assay were $93.04 \mathrm{~g} / \mathrm{L}$ of ethanol concentration corresponding to 94.3 of ethanol yield (Table 2, run 16). These results showed a relative error of $7.44 \%$ for ethanol concentration and $6.04 \%$ for ethanol yield. These data verify the sustainability of the model for reproducing and predicting the experimental results.

The integration of CWP in lignocellulose-to-ethanol processes increases the source of carbon and provides a source of nitrogen, required 
a)

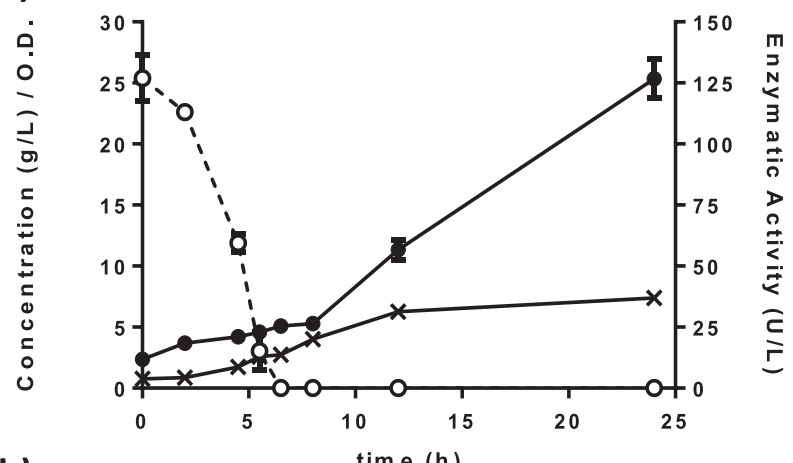

b)

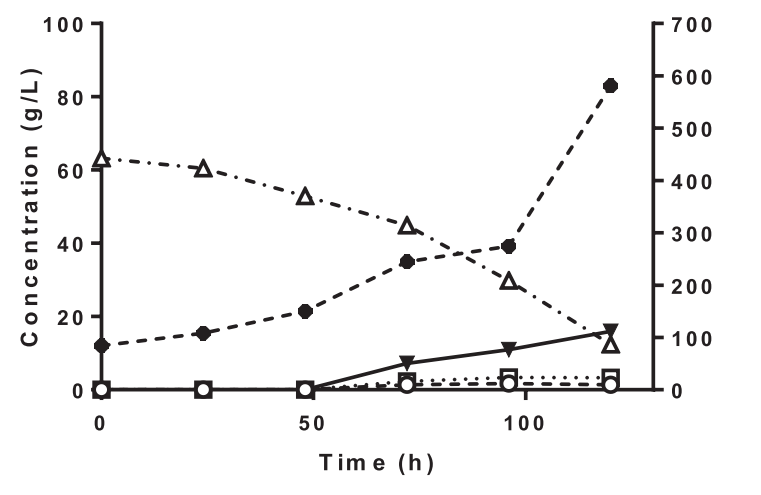

Fig. 4. Fermentation profiles of recombinant Ethanol Red ${ }^{\circledR}$ pMC1 strain in different culture conditions: a) $\beta$-galactosidase production in standard YPD medium (data are average values for two independent experiments); b) $\beta$-galactosidase production and lactose consumption in a cheese whey based-medium; c) Simultaneous saccharification and fermentation of $5 \%$ of pretreated Eucalyptus wood and $2 \%$ of cheese whey at cellulase loading of $24.23 \mathrm{FPU} / \mathrm{g}$.

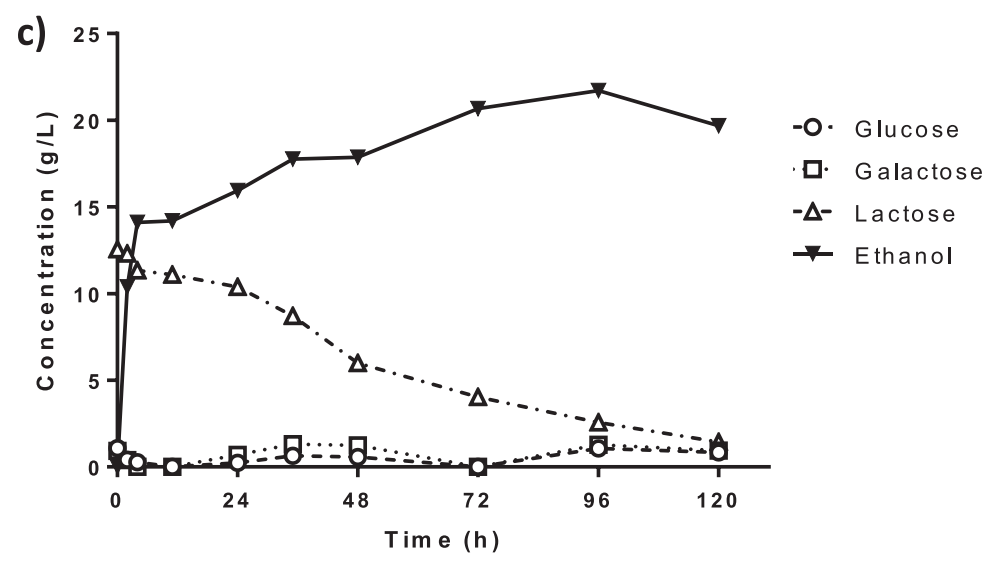

for a nutritionally balanced fermentation (Kargi, and Ozmihc1, 2006). In this sense, an additional SSF experiment without CWP was carried out to quantify the improvement of the process with the CWP supplementation (Fig. 1g, run 17). Taking into account the superiority of industrial strains in lignocellulose-to-ethanol fermentation (Pereira et al., 2014; Cunha et al., 2015; Costa et al., 2017), a laboratory S. cerevisiae (CEN.PK113-7D) strain was used for comparison under the same conditions with and without CWP supplementation (Fig. 1f, run 18). Main results from these SSF assays under optimized conditions are listed in Table 3. Ethanol Red ${ }^{\circledR}$ strain clearly shows a superior fermentation performance, practically consuming all sugars (Fig. $1 \mathrm{~g}$ ), while $17.0 \mathrm{~g} / \mathrm{L}$ of glucose and $29.2 \mathrm{~g} / \mathrm{L}$ of galactose remained to be consumed by CEN.PK 113-7D at the end of the experiment (Fig. 1f). These results show the importance of selecting robust yeast strains for intensified fermentation conditions (such as high temperature and elevated solid loading). On the other hand, higher ethanol concentrations (1.5-fold) were obtained by the two $S$. cerevisiae strains when the cheese whey was mixed with Eucalyptus wood due to the increment of total sugars. Moreover, the addition of cheese whey improved the ethanol yield obtained by laboratory and industrial strains (11.84 and $12.64 \%$, respectively). The mixing of CWP with pretreated EGW also improved the ethanol productivity of SSF. The ethanol productivity at $48 \mathrm{~h}\left(\mathrm{Qp}_{48 \mathrm{~h}}\right)$ for Ethanol $\operatorname{Red}^{\otimes}$ was $1.7 \mathrm{~g} / \mathrm{Lh}$ with cheese whey and $1.18 \mathrm{~g} / \mathrm{Lh}$ without cheese whey. On the other hand, the ethanol productivity of CEN.PK 113-7D at $48 \mathrm{~h}$ was $1.21 \mathrm{~g} / \mathrm{Lh}$ with cheese whey and $1.13 \mathrm{~g} / \mathrm{Lh}$ without cheese whey. Similar ethanol productivity $(1.8 \mathrm{~g} / \mathrm{Lh})$ using cheese whey as sole carbon source and a $K$. fragilis (Kf1), isolated from cocoa fermentation, was reported by Dragone et al. (2011). Ethanol Red $^{\circledR}$ showed better fermentation capacity, consuming glucose and galactose simultaneously, while the laboratory strain was unable to ferment galactose in the presence of glucose, probably due to catabolite repression effect.

\subsection{Recombinant Ethanol Red ${ }^{\circledast}$ strain for $\beta$-galactosidase secretion: integration in the SSF of EGW and CWP mixture for ethanol production}

Considering the obtained results for the SSF process of substrate mixture at $35^{\circ} \mathrm{C}$ and high solids loading with Ethanol Red ${ }^{\circledast}$ strain, we selected this industrial strain as host for recombinant $\beta$-galactosidase secretion in order to advance towards an integrated process. Ethanol $\operatorname{Red}^{\circledR}$ was transformed with the pMC1 plasmid, a multi-copy expression vector based on pVK1.1, containing the $\beta$-galactosidase expression 
cassette and a dominant selection marker (GEN3), allowing its use in prototrophic strains. $\beta$-Galactosidase expression by Ethanol Red ${ }^{\circledR}$-pMC1 was firstly assessed on shake flask experiments in standard YPD medium (Fig. 4a). As expected, glucose was rapidly exhausted $(24 \mathrm{~g} / \mathrm{L}$ under $7 \mathrm{~h}$ ) and $\beta$-galactosidase activity levels reached approximately $130 \mathrm{U} / \mathrm{L}$ at the end of the experiments. The recombinant strain was then assayed in a cheese whey powder based-medium $\left(30^{\circ} \mathrm{C}\right.$ and $\left.200 \mathrm{rpm}\right)$ in order to quantify the enzyme production and its capacity to hydrolyze lactose and produce ethanol, as depicted in Fig. 4b. $60 \mathrm{~g} / \mathrm{L}$ of lactose were hydrolyzed in $125 \mathrm{~h}$, being glucose immediately consumed, while galactose consumption was slower. $\beta$-Galactosidase activity levels reached almost $600 \mathrm{U} / \mathrm{L}$ at the end of the experiment, while ethanol concentration was just below $20 \mathrm{~g} / \mathrm{L}$ (Fig. 4b). Domingues et al. (2002) and Oliveira et al. (2007) obtained higher $\beta$-galactosidase expression levels in Semi Synthetic lactose 5\% (SSLactose) with recombinant strains NCYC869-A3/pVK1.1 and NCYC869/p8neo + lacA, around $2000 \mathrm{U} / \mathrm{L}$ and $25 \mathrm{~g} / \mathrm{L}$ ethanol. However, as already mentioned, in order to develop an intensified process, robust industrial strains are required.

The $\beta$-galactosidase activity levels obtained with recombinant Ethanol Red $^{\circledR}$-pMC1 strain were very low in comparison with those used in the experimental design. In this sense, the use of recombinant strain in SSF process for fermentation of EGW and CWP mixture was carried out with $5 \%$ of EGW and $2 \%$ of cheese whey (corresponding to $1.2 \%$ of lactose) in order to increase the enzyme to substrate ratio. Fig. 4c shows time course of SSF assays with CWP and EGW mixture. Lactose was consumed within $120 \mathrm{~h}$ of fermentation. No galactose accumulation was observed in the medium $(<1.3 \mathrm{~g} / \mathrm{L})$, which shows a good performance of recombinant strain for both sugars (glucose and galactose) uptake. Ethanol concentration achieved $21.7 \mathrm{~g} / \mathrm{L}$ (corresponding to $96 \%$ of ethanol yield). Under these operational conditions, results obtained from simultaneous saccharification and fermentation of renewable sources (CWP and EGW) mixture were quite satisfactory proving the feasibility of this consolidated approach. The level of $\beta$-galactosidase expression should now be fine-tuned in the recombinant yeast. In addition, $\beta$-galactosidase secretion can also be optimized by process conditions (Castro et al., 2012). To the best of our knowledge, this is the first time that an integrated strategy using recombinant industrial strain for multi-waste valorization into bioethanol was carried out.

\section{Conclusions}

SSF process was optimized to obtain high ethanol concentration ( $93 \mathrm{~g} / \mathrm{L}$ corresponding to $94 \%$ of ethanol yield) using a mixture of pretreated EGW and CWP under a multi-wastes valorization approach. The integration of cheese whey in EGW fermentation together with the use of a robust thermotolerant yeast strain boosted the ethanol concentration in 1.5-fold comparing to results obtained without CWP. Furthermore, and for the first time, an industrial strain was engineered for $\beta$-galactosidase production to evolve towards an integrated process. Recombinant strain successfully fermented lactose from cheese whey, as well as, the mixture of eucalyptus wood and cheese whey.

\section{Acknowledgements}

This study was supported by the Portuguese Foundation for Science and Technology (FCT) under the scope of the strategic funding of UID/ BIO/04469/2013 unit and COMPETE 2020 (POCI-01-0145-FEDER006684) and BioTecNorte operation (NORTE-01-0145-FEDER-000004) funded by European Regional Development Fund under the scope of Norte2020 - Programa Operacional Regional do Norte.

\section{References}

Balat, M., 2011. Production of bioethanol from lignocellulosic materials via the biochemical pathway: a review. Energy Convers. Manage. 52, 858-875.

Belinchón, M.M., Gancedo, J.M., 2003. Xylose and some non-sugar carbon sources cause catabolite repression in Saccharomyces cerevisiae. Arch. Microbiol. 180 (4), 293-297. Cai, J., He, Y., Yu, X., Banks, S., Yang, Y., Zhang, X., Yu, Y., Liu, R., Bridgwater, A.V. 2017. Review of physiochemical properties and analytical characterization of lignocellulosic biomass. Renew. Sustain. Energy Rev. 76, 309-322.

Castro, I., Oliveira, C., Domingues, L., Teixeira, J.A., Vicente, A., 2012. The effect of the electric field on lag-phase, $\beta$-galactosidase production and plasmid stability of a recombinant Saccharomyces cerevisiae strain growing on lactose. Food Bioprocess. Technol. 5, 3014-3020.

Coman, G., Andreea, N., Constanta, S., Bahrim, G., 2015. Bioethanol production by solid state fermentation from cheese whey mixed with brewer's spent grains. Ann. Univ. Dunarea JosGalati Fascicle VI-Food Technol. 39, 49-57.

Costa, C.E., Romaní, A., Cunha, J.T., Johansson, B., Domingues, L., 2017. Integrated approach for selecting efficient Saccharomyces cerevisiae for industrial lignocellulosic fermentations: importance of yeast chassis linked to process conditions. Bioresour. Technol. 227, 24-34.

Cunha, J.T., Aguiar, T.Q., Romaní, A., Oliveira, C., Domingues, L., 2015. Contribution of PRS3, RPB4 and ZWF1 to the resistance of industrial Saccharomyces cerevisiae CCUG53310 and PE-2 strains to lignocellulosic hydrolysate-derived inhibitors. Bioresour. Technol. 191, 7-16.

Domingues, L., Teixeira, J.A., Penttilä, M., Lima, N., 2002. Construction of a flocculent Saccharomyces cerevisiae strain secreting high levels of Aspergillus niger $\beta$-galactosidase. Appl. Microbiol. Biotechnol. 58, 645-650.

Domingues, L., Oliveira, C., Castro, I., Lima, N., Teixeira, J.A., 2004. Production of $\beta$ -galactosidase from recombinant Saccharomyces cerevisiae grown on lactose. J. Chem. Technol. Biotechnol. 79, 809-815.

Domingues, L., Lima, N., Teixeira, J.A., 2005. Aspergillus niger $\beta$-galactosidase production by yeast in a contiuous high cell density reactor. Process. Biochem. 40, 1151-1154.

Dominguez, E., Romaní, A., Domingues, L., Garrote, G., 2017. Evaluation of strategies for second generation bioethanol production from fast growing biomass Paulownia within a biorefinery scheme. Appl. Energy 187, 777-789.

Dragone, G., Mussatto, S.I., Almeida e Silva, J.B., Teixeira, J.A., 2011. Optimal fermentation conditions for maximizing the ethanol production by Kluyveromyces fragilis from cheese whey powder. Biomass Bioenergy 35, 1977-1982.

Ferreira, P.G., da Silveira, F.A., dos Santos, R.C.V., Genier, H.L.A., Diniz, R.H.S., Ribeiro, J.I., Fietto, L.G., Passos, F.M.L., da Silveira, W.B., 2015. Optimization ethanol production by thermotolerant Kluyveromyces marxianus CCT 7735 in a mixture of sugarcane bagasse and ricotta whey. Food Sci. Biotechnol. 24 (4), 1421-1427.

Fischer, J., Lopes, V.S., Galvão, C.M.A., Teodoro, J.C., Filho, U.C., Cardoso, V.L., 2013. Utilization of cheese whey and cellulosic biomass production of ethanol by selected fungi strain from brazilian savanas. Chem. Eng. Trans. 32, 1075-1080.

Ghose, T.K., 1987. Measurement of cellulase activities. Pure Appl. Chem. 59, 257-268.

Gietz, R., Schiestl, R., 2007. High-efficiency yeast transformation using the LiAc/SS carrier DNA/PEG method. Nat. Protoc. 2, 31-34.

Guimarães, P.M., Teixeira, J.A., Domingues, L., 2008. Fermentation of high concentrations of lactose to ethanol by engineering flocculent Saccharomyces cerevisiae. Biotechnol. Lett. 30 (11), 1953-1958.

Guimarães, P.M., Teixeira, J.A., Domingues, L., 2010. Fermentation of lactose to bioethanol by yeasts as part of integrated solutions for the valorisation of cheese whey. Biotechnol. Adv. 28 (3), 375-384.

Hasunuma, T., Kondo, A., 2012. Development of yeast cell factories for consolidated bioprocessing of lignocellulose to bioethanol through cell surface engineering. Biotechnol. Adv. 30 (6), 1207-1218.

Jin, Y., Parashar, A., Mason, B., Bressler, D., 2016. Simultaneous hydrolysis and co-fermentation of whey lactose with wheat for ethanol production. Bioresour. Technol. 221, 616-624.

Jones, D.B., 1941. Factors for Converting Percentages of Nitrogen in Foods and Feeds into Percentages of Proteins. Circular No. 183. United States Department of Agriculture, Washington, DC, USA.

Kargi, K., Ozmıhc1, S., 2006. Utilization of cheese whey poder (CWP) for ethanol fermentations: effects of operating parameters. Enzyme Microbiol. Technol. 38, $711-718$.

Kelbert, M., Romaní, A., Coelho, E., Pereira, F.B., Teixeira, J.A., Domingues, L., 2015 Lignocellulosic bioethanol production with revalorization of low-cost agroindustrial by-products as nutritional supplements. Ind. Crops Prod. 64, 16-24.

Kelbert, M., Romaní, A., Coelho, E., Pereira, F.B., Teixeira, J.A., Domingues, L., 2016. Simultaneous saccharification and fermentation of hydrothermal pretreated lignocellulosic biomass: evaluation of process performance under multiple stress conditions. Bioenergy Res. 93 (3), 750-762.

Kroppam, R., Tomás-Pejó, E., Xiros, C., Olsson, L., 2014. Lignocellulosic ethanol production at high-gravity: challenges and perspectives. Trends Biotechnol. 32 (1), 46-53.

Kumar, V., Ramakrishnan, S., Teeri, T.T., Knowles, J.K.C., Hartley, B.S., 1992. Saccharomyces cerevisiae cells secreting an Aspergillus niger $\beta$-galactosidase grow on whey permeate. Bio/Technology 10, 82-85.

Menon, V., Rao, M., 2012. Trends in bioconversion of lignocellulose: biofuels, platform chemicals and biorefinery concept. Prog. Energy Combust. Sci. 38, 522-550.

Nakamura, K., Shinomiya, N., Orikasa, Y., Oda, Y., 2012. Efficient production of ethanol from saccharified crops mixed with cheese whey by the flex yeast Kluyveromyces marxianus KD-15. Food Sci. Technol. Res. 18 (2), 235-242.

Oke, M.A., Annuar, M.S.M., Simarani, K., 2016. Mixed feedstock approach to lignocellulosic ethanol production-prospects and limitations. Bioenergy Res. 19, 1189-1203.

Oliveira, C., Teixeira, J.A., Lima, N., da Silva, N.A., Domingues, L., 2007. Development of stable flocculent Saccharomyces cerevisiae strain for continuous Aspergillus niger $\beta$ galactosidase production. J. Biosci. Bioeng. 103, 318-324.

Oliveira, C., Guimarães, P.M.R., Domingues, L., 2011. Recombinant microbial systems for 
improved $\beta$-galactosidase production and biotechnological applications. Biotechnol. Adv. 29, 600-609.

Olofsson, K., Bertilsson, M., Lidén, G., 2008. A short review on SSF-an interesting process option for ethanol production from lignocellulosic feedstock. Biotechnol. Biofuels 1,7 .

Parashar, A., Jin, Y., Mason, B., Chae, M., Bressler, D.C., 2016. Incorporation of whey permeate, a dairy effluent, in ethanol fermentation to provide a zero waste solution for the dairy industry. J. Dairy Sci. 99 (3), 1859-1867.

Pereira, F.B., Romaní, A., Ruiz, H.A., Teixeira, J.A., Domingues, L., 2014. Industrial robust yeast isolates with great potential for fermentation of lignocellulosic biomass. Bioresour. Technol. 161, 192-199.

Rodionova, M.V., Poudyal, R.S., Tiwari, I., Voloshin, R.A., Zharmukhanmedov, S.K., Nam, H.G., Zayadan, B.K., Bruce, B.D., Hou, H.J.M., Allakhverdiev, S.I., 2017. Biofuel production: challenges and opportunities. Int. J. Hydrogen Energy 42 (12), 8450-8461.

Romaní, A., Garrote, G., Alonso, J.L., Parajó, J.C., 2010. Experimental assessment on the enzymatic hydrolysis of hydrothermally pretreated Eucalyptus globulus wood. Ind. Eng. Chem. Res. 49, 4653-4663.

Romaní, A., Garrote, G., Parajó, J.C., 2012. Bioethanol production from autohydrolyzed Eucalyptus globulus by simultaneous saccharification and fermentation operating at high solids loading. Fuel 94, 305-312.

Romaní, A., Ruiz, H.A., Pereira, F.B., Teixeira, J.A., Domingues, L., 2014. Integrated approach for effective bioethanol production using whole slurry from autohydrolyzed Eucalyptus globulus wood at high-solid loadings. Fuel 135, 482-491.

Romaní, A., Pereira, F., Johansson, B., Domingues, L., 2015. Metabolic engineering of Saccharomyces cerevisiae ethanol strains PE-2 and CAT-1 for efficient lignocellulosic fermentation. Bioresour. Technol. 179, 150-158.

Sansonetti, S., Curcio, S., Calabró, V., Iorio, G., 2010. Optimization of ricotta cheese whey (RCW) fermentation by response Surface methodology. Bioresour. Technol. 101, 9156-9162.

Tomás-Pejó, E., Negro, M.J., Sáez, F., Ballesteros, M., 2012. Effect of nutrient additionon preinoculum growth of $S$. cerevisiae for application in SSF processes. Biomass Bioenergy 45, 168-174.

Trigueros, D.E.G., Fiorese, M.L., Kroumov, A.D., Hinterholz, C.I., Nadai, B.L., Assunção, G.M., 2016. Medium optimization and kinetics modeling for the fermentation of hydrolyzed cheese whey permeate as substrate for Saccharomyces cerevisiae var. boulardii. Biochem. Eng. J. 110, 71-83.

Vargas, F., Domínguez, E., Vila, C., Rodríguez, A., Garrote, G., 2015. Agricultural residue valorization using a hydrothermal process for second generation bioethanol and oligosaccharide production. Bioresour. Technol. 191, 263-270.

Yadav, J.S.S., Yan, S., Pilli, S., Kumar, L., Tyagi, R.D., Surampalli, R.Y., 2015. Cheese whey: a potential resource to transform into bioprotein, functional/nutritional proteins and bioactive peptides. Biotechnol. Adv. 33 (6), 756-774. 